7. Beiondere Fälle:

$\S 20$. a) Radjerbfolge

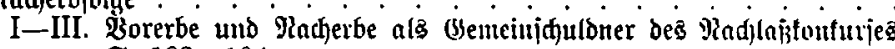
ธ. $103-104$.

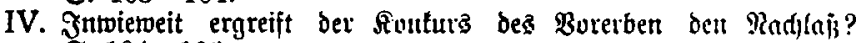
ร. $104-106$.

§ 21. b) Erbiałaftofauf

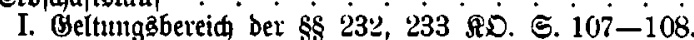

II. Zwed bea \& 232 I S. 108 .

III. Jnfalt bes § 232 ฐ. $109-111$.

IV. Berwanbte J̛ălle S. 111.

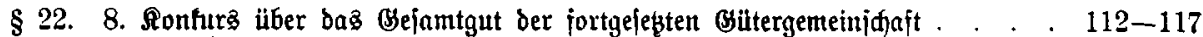

I. Begriff unto Bebeutung biejez Berfahtens 5 . 112-115.

II. Eroffinung 5 . $115-116$.

III. Benteintidulbner S. 116.

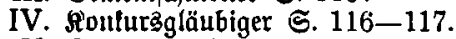

V. Runtursmajie S. 117.

VI. fionlurabeenbigung 5.117.

\title{
Dite Haterialien
}

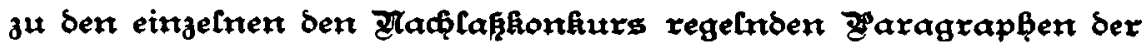
Honfuxsordnung Find autammengeltellt

\begin{tabular}{|c|c|c|c|c|c|}
\hline$x \geq 21$ & & & & & \\
\hline " $\$ 215$ & " & $"$ & 36 & $"$ & $"$ \\
\hline$" \$ 216$ & $"$ & $"$ & 32 & ״ & $"$ \\
\hline " $\$ 217$ & $"$ & $"$ & 39 & $"$ & 1 \\
\hline$\S 218$ & $"$ & " & 38 & $"$ & " \\
\hline$\$ 219$ & $"$ & $"$ & 41 & $"$ & 19 \\
\hline " \& 220 & $"$ & $"$ & 44 & $"$ & 32 \\
\hline$\$ 2: 21$ & $"$ & " & 58 & $"$ & 44 \\
\hline$\S 222$ & $"$ & $"$ & 57 & $"$ & 39 \\
\hline$\$ 223$ & $"$ & $"$ & $8 t$ & $"$ & 11 \\
\hline " $\$ 224$ & " & $"$ & 76 & $"$ & 1 \\
\hline 8245 & $"$ & $"$ & 81 & $"$ & 1 \\
\hline$\$ 226$ & $"$ & ״ & 68 & $"$ & 29 \\
\hline$\$ 227$ & $"$ & $"$ & 72 & $"$ & 41 \\
\hline$\$ 2 \cdot 28$ & $"$ & $"$ & 72 & $"$ & 43 \\
\hline " $\$ 229$ & $"$ & " & 74 & $"$ & 51 \\
\hline$\S 230$ & $"$ & $"$ & 87 & - & 1 \\
\hline$\S 231$ & $"$ & $"$ & 104 & $"$ & 1 \\
\hline " $\$ 232$ & $"$ & $"$ & 107 & $"$ & " \\
\hline " \$233 & $"$ & $"$ & 107 & $"$ & 1 \\
\hline " \$234 & $"$ & $"$ & 100 & $"$ & 3 \\
\hline " $\$ 235$ & $"$ & $"$ & З’う & $"$ & 17 \\
\hline$\S 236$ & $"$ & $"$ & 112 & $"$ & $=1$ \\
\hline
\end{tabular}

Die Dtaterialien zu \& 9 尺D. finben fid auf Geite 93 in Note 1 , " " \$ $128 \mathfrak{R D}$ " " " 105 " 8 . 